\title{
Lack of efficacy of a partial adenosine $A 1$ receptor agonist in neuropathic pain models in mice
}

\author{
Katharina Metzner ${ }^{1} \cdot$ Tilman Gross $^{1} \cdot$ Annika Balzulat $^{1} \cdot$ Gesine Wack $^{1} \cdot$ Ruirui Lu $^{1} \cdot$ Achim Schmidtko $^{1}$
}

Received: 19 December 2020 / Accepted: 28 June 2021 / Published online: 27 July 2021

(c) The Author(s) 2021

\begin{abstract}
Previous studies suggest that adenosine $A_{1}$ receptors $\left(A_{1} R\right)$ modulate the processing of pain. The aim of this study was to characterize the distribution of $A_{1} R$ in nociceptive tissues and to evaluate whether targeting $A_{1} R$ with the partial agonist capadenoson may reduce neuropathic pain in mice. The cellular distribution of $A_{1} R$ in dorsal root ganglia (DRG) and the spinal cord was analyzed using fluorescent in situ hybridization. In behavioral experiments, neuropathic pain was induced by spared nerve injury or intraperitoneal injection of paclitaxel, and tactile hypersensitivities were determined using a dynamic plantar aesthesiometer. Whole-cell patch-clamp recordings were performed to assess electrophysiological properties of dissociated DRG neurons. We found $\mathrm{A}_{1} \mathrm{R}$ to be expressed in populations of DRG neurons and dorsal horn neurons involved in the processing of pain. However, administration of capadenoson at established in vivo doses $(0.03-1.0 \mathrm{mg} / \mathrm{kg})$ did not alter mechanical hypersensitivity in the spared nerve injury and paclitaxel models of neuropathic pain, whereas the standard analgesic pregabalin significantly inhibited the pain behavior. Moreover, capadenoson failed to affect potassium currents in DRG neurons, in contrast to a full $A_{1} R$ agonist. Despite expression of $A_{1} R$ in nociceptive neurons, our data do not support the hypothesis that pharmacological intervention with partial $\mathrm{A}_{1} \mathrm{R}$ agonists might be a valuable approach for the treatment of neuropathic pain.
\end{abstract}

Keywords Neuropathic pain · Adenosine $\mathrm{A}_{1}$ receptor · Partial agonist · Pain behavior · In situ hybridization · Patch-clamp

\section{Introduction}

Traumatic injuries, surgical insults and damages of peripheral nerves often lead to neuropathic pain, a chronic debilitating disease that affects $7-10 \%$ of the general population and is associated with great impairment of quality of life [1]. However, more than half of neuropathic pain patients report inadequate pain relief with currently available medications, and these are often associated with severe dose-limiting side effects. Therefore, there is a large unmet therapeutic need for effective and safe treatment of neuropathic pain [2-4].

Neuropathic pain is associated with multiple alterations in the peripheral and central nervous system [5, 6]. Accumulating evidence indicates that the nucleoside adenosine contributes to the processing of neuropathic pain $[7,8]$. In general, adenosine interacts with four $\mathrm{G}$ protein-coupled

Katharina Metzner

metzner@em.uni-frankfurt.de

1 Institute of Pharmacology and Clinical Pharmacy, Goethe University Frankfurt, 60438 Frankfurt am Main, Germany receptors, $A_{1} R, A_{2 A} R, A_{2 B} R$ and $A_{3} R$, which in turn affect the activity of various ion channels and enzymes [9]. Among the adenosine receptors, $A_{1} R$ has gained interest in pain research. Previous studies reported that $A_{1} R$ is expressed in both peripheral and central sites of the nociceptive system, although the cellular distribution remains controversial [10-13]. Several lines of evidence indicate the functional contribution of $A_{1} R$ to neuropathic pain processing. For example, mice lacking $A_{1} R$ globally demonstrated increased pain behaviors in models of neuropathic pain [14]. Increasing adenosine levels by delivery of ectonucleotidases that dephosphorylate adenosine 5'-monophosphate to adenosine is associated with potent, long-lasting, and $\mathrm{A}_{1} \mathrm{R}$-dependent antinociceptive effects $[15,16]$. Furthermore, administration of $\mathrm{A}_{1} \mathrm{R}$ agonists such as $\mathrm{N}^{6}$-cyclopentyladenosine (CPA) or 5'-chloro-5'deoxy-( \pm )-ENBA (Cl-ENBA) ameliorated neuropathic pain in various animal models (for review, see [7]).

Although numerous full $A_{1} R$ agonists have been developed, clinical applications of these agents have been hampered by unintended pharmacological effects including sedation, motor impairment, bradycardia and atrioventricular 
blocks $[17,18]$. These unwanted effects can be overcome by partial $A_{1} R$ agonists, which trigger only some of the physiological responses of receptor activation depending on endogenous adenosine levels and on receptor reserve in different tissues [19]. Partial $A_{1} R$ agonists might therefore hypothetically ameliorate neuropathic pain in an effective and safe manner. Among the selective and potent partial $A_{1} R$ agonists is capadenoson, which belongs to the nonadenosine dicyanopyridine class of compounds. Capadenoson shows $\mathrm{EC}_{50}$ values of $0.1 \mathrm{nM}$ on $\mathrm{A}_{1} \mathrm{R}$, a selectivity factor of 1800 and 900 versus $A_{2 A} R$ and $A_{2 B} R$, respectively, and no significant activity on $A_{3} R$ [19]. Furthermore, it exhibits good pharmacokinetic parameters with sufficient bioavailability after oral administration $[18,19]$. The primary objectives of the study were to characterize the cellular distribution of $A_{1} R$ in nociceptive tissues and to investigate whether targeting $\mathrm{A}_{1} \mathrm{R}$ using the partial agonist capadenoson might inhibit neuropathic pain in mice.

\section{Material and methods}

\section{Animals}

All experiments were performed in C57BL/6 N mice of either sex (6-12 weeks old) obtained from Charles River Laboratories (Sulzfeld, Germany). Animals were housed on a $12 \mathrm{~h} \mathrm{light/dark} \mathrm{cycle} \mathrm{with} \mathrm{access} \mathrm{to} \mathrm{food} \mathrm{and} \mathrm{water} \mathrm{ad} \mathrm{libi-}$ tum. All behavioral studies were carried out by observers blinded for treatment of the animals. All experiments were ethically reviewed and approved by our local Ethics Committee for Animal Research (Regierungspräsidium Darmstadt, Germany). They adhered to the IASP (International Association for the Study of Pain) and ARRIVE (Animal Research: Reporting on In Vivo Experiments) guidelines and conformed to Directive 2010/63/EU. All efforts were made to minimize animal suffering and to reduce the number of animals used.

\section{Neuropathic pain models}

The spared nerve injury (SNI) model [20] was used to investigate neuropathic pain behavior after surgically induced peripheral nerve injury. Animals were treated with carprofen $(5 \mathrm{mg} / \mathrm{kg}$, s.c.) $30 \mathrm{~min}$ prior to surgery to provide perioperative and postoperative analgesia. Under isoflurane anesthesia, two branches of the sciatic nerve were ligated and cut distally, leaving the sural nerve intact. This procedure leads to a hypersensitivity of the lateral surface (sural nerve skin area) of the affected hindpaw.

The paclitaxel model of neuropathy was used to mimic chemotherapy-induced neuropathic pain behavior. Animals received four i.p. injections of $1 \mathrm{mg} / \mathrm{kg}$ paclitaxel on days 0 ,
2, 4 and 6 (cumulative dose $4 \mathrm{mg} / \mathrm{kg}$; [21]. Paclitaxel (Sigma Aldrich, Germany) was dissolved in a vehicle composed of Cremophor EL and absolute ethanol (1:1) and was further diluted in $0.9 \% \mathrm{NaCl}[22,23]$.

Mechanical sensitivity of the hindpaw was measured using a Dynamic Plantar Aesthesiometer (Ugo Basile, Italy). This device pushes a thin steel rod against the plantar surface of the paw from beneath, and automatically stops and records the latency time until the animal withdraws the paw. The force increased constantly from 0 to $5 \mathrm{~g}$ in $10 \mathrm{~s}$ (ramp $0.5 \mathrm{~g} / \mathrm{s}$ ) and remained at $5 \mathrm{~g}$ for an additional $10 \mathrm{~s}$ [23-25]. The paw withdrawal latency was calculated as the mean of 4-5 consecutive measurements with at least $20 \mathrm{~s}$ in between. Baseline measurements of mechanical sensitivity were performed 2 and 1 days before SNI surgery or paclitaxel injections. To ensure full development of neuropathic pain, mechanical sensitivity of the hindpaw was determined 13 or 20 days after SNI and 6 days after the last paclitaxel injection. One day thereafter, capadenoson (provided by Bayer AG, Germany, and purchased from MedChemExpress, USA), pregabalin (Bertin, France and Neuraxpharm, Germany), or vehicle (85\% PEG400 and 15\% glycerol; both from Carl Roth, Germany) were administered by oral gavage, whereas in another set of experiments capadenoson, N-Bicyclo[2.2.1] hept-2-yl-5' -chloro-5' -deoxyadenosine (CL-ENBA; Tocris, UK) or vehicle (60\% PEG400 in water; Carl Roth, Germany) were administered by tail vein injection. The mechanical sensitivity of the ipsilateral hindpaw was determined over $24 \mathrm{~h}$ after drug administration.

\section{In situ hybridization}

Mice were killed by $\mathrm{CO}_{2}$ inhalation and perfused with $4 \%$ formaldehyde (PFA) in phosphate-buffered saline (PBS) for 5 min. Lumbar (L4-L5) spinal cords and lumbar (L4L5) DRGs were dissected, post-fixed in PFA for $10 \mathrm{~min}$, incubated in 20\% sucrose in PBS overnight, and embedded in tissue freezing medium (Leica, Germany). Cryostat sections were cut at a thickness of $14 \mu \mathrm{m}$ on a CryoStar NX50 device (Thermo Fisher Scientific, Germany). In situ hybridization (ISH) was performed using a QuantiGene ViewRNA Tissue Assay (Thermo Fisher Scientific, Germany) according to the manufacturer's instructions and as previously described [26]. Briefly, probes for mouse Adora1 (diluted 1:40; NM_001039510.2, type 1 probe set, catalog \# VB1-19,627, Thermo Fisher, Germany), Rbfox3 (diluted 1:40; NM_001039167.1, type 6 probe set, catalog \# VB6$18,012)$ and scramble control $(1: 40$; catalog \# VF1-17,155) were incubated overnight at $40{ }^{\circ} \mathrm{C}$ (Thermobrite; Leica, Germany) followed by consecutive incubation with PreAmplifier Mix QT, Amplifier Mix QT, an alkaline phosphatase labeled probe against the Amplifier, AP Enhancer Solution, and Fast Red Substrate. Finally, sections were mounted 
with Fluoromount G (Southern Biotech, USA) or further processed for subsequent immunostaining.

In immunostaining experiments after in situ hybridization, sections were blocked in $10 \%$ normal goat serum (NGS), 3\% bovine serum albumin (BSA) and 1\% Triton $\mathrm{X}-100$ in PBS for $1 \mathrm{~h}$ and incubated with primary antibodies overnight using rabbit anti-NF200 (1:2000; \# N4142, Sigma-Aldrich, Germany) and rabbit anti-CGRP (1:800, \# PC205C, Calbiochem, Germany). After rinsing in PBS, sections were incubated with secondary antibodies conjugated with Alexa Fluor 488 (Invitrogen/Life Technologies, USA) for $2 \mathrm{~h}$ at room temperature. For staining with Griffonia simplicifolia isolectin B4 (IB4), sections were incubated with AF488-labelled IB4 (\# I21411, Invitrogen/Life Technologies, USA; dissolved 1:300 in PBS buffer containing $1 \mathrm{mM} \mathrm{CaCl} 2,1 \mathrm{mM} \mathrm{MgCl} 2,1 \mathrm{mM} \mathrm{MnCl}_{2}$, and $0.2 \%$ Triton $\mathrm{X}-100, \mathrm{pH}$ 7.4) for $1 \mathrm{~h}$ at room temperature. Slides were coverslipped with Fluoromount G (Southern Biotech, USA). Images were taken using an Eclipse Ni-U microscope equipped with a monochrome DS-Qi2 camera (both from Nikon, Germany) and pseudocolored with the NIS Elements software (Nikon, Germany).

\section{Cell counting}

For quantification of $A_{1} R$ mRNA-positive sensory and dorsal horn neuron populations, serial sections of lumbar DRGs (L4-L5) and the lumbar spinal cord (L4-L5) from 3 mice were cut $(14 \mu \mathrm{m})$. Per animal, $\geq 3$ DRG sections at least $100 \mu \mathrm{m}$ apart were counted manually (4837 cells in total). Only cells showing clear staining signals above background level, with a threshold set based on scramble control hybridization, were included. The percentage of CGRP-, IB4- and NF200-positive neurons is expressed as a proportion of marker-positive cells per total number of $A_{1} R$-positive neurons. For calculation of the percentage of $\mathrm{A}_{1} \mathrm{R}$-positive DRG neurons, the total number of DRG neuron somata was counted based on their autofluorescence visualized in the FITC channel.

\section{DRG neuron culture}

Mice (4-8 weeks old) were killed by $\mathrm{CO}_{2}$ inhalation and lumbar DRGs (L4-L5) were excised and transferred to HBSS (Thermo Fisher Scientific, USA). Following treatment with $2.5 \mathrm{U} / \mathrm{ml}$ dispase II and $500 \mathrm{U} / \mathrm{ml}$ collagenase IV (both from Roche, Switzerland) for $90 \mathrm{~min}$ and $0.05 \%$ Trypsin/EDTA (Thermo Fisher Scientific, USA) for $10 \mathrm{~min}$, isolated cells were transferred onto coverslips coated with poly-d-lysine ( $250 \mu \mathrm{g} / \mathrm{ml}$, Millipore, USA) and cultured in neurobasal medium supplemented with B27 (Thermo Fisher Scientific, USA), $100 \mu \mathrm{g} / \mathrm{ml}$ streptomycin and penicillin (Roth,
Germany) at $37^{\circ} \mathrm{C}$ and $5 \% \mathrm{CO}_{2}$. Cells were used for experiments within $24 \mathrm{~h}$ after plating.

\section{Electrophysiological recordings}

Whole-cell voltage-clamp recordings on DRG neurons were performed at room temperature $\left(20-22{ }^{\circ} \mathrm{C}\right)$, using an HEKA EPC 9 amplifier and Patchmaster software (HEKA Electronics, Germany). Offline analysis was performed using the Fitmaster software (HEKA Electronics, Germany) and GraphPad Prism 8. Micropipettes (3-5 M $\Omega$ ) were pulled from borosilicate glass (Science Products, Germany) with a conventional micropipette puller (Model P-97, Sutter Instruments, USA). Potassium currents were measured by continuous perfusion of the external solution with clamp steps of $500 \mathrm{~ms}$ between -100 and $+120 \mathrm{mV}$ starting from a $1000 \mathrm{~ms}$ prepulse at $-100 \mathrm{mV}$. The holding potential was $-70 \mathrm{mV}$. Current densities were normalized to the cell capacitance (pA/pF). The pipette solution contained (mM): $\mathrm{KCl} \mathrm{140,}$ $\mathrm{MgCl}_{2}$ 2, EGTA 5, HEPES 10, MgATP 2, TrisGTP 1, pH 7.4 adjusted with $\mathrm{KOH}$. The external solution contained (mM): $\mathrm{NaCl} 140, \mathrm{KCl} 5, \mathrm{CaCl}_{2} 2, \mathrm{MgCl}_{2}$ 2, HEPES 10, pH 7.4 adjusted with $\mathrm{NaOH}$. Capadenoson or CPA (Sigma-Aldrich, Germany), solved in external solution with a final concentration of $100 \mathrm{nM}$, were added to the bath without a continuous perfusion. Potassium currents were measured within $10 \mathrm{~min}$ after drug addition.

\section{Statistical analysis}

GraphPad Prism 8 software was used for statistical analysis. A two-way repeated-measures ANOVA with Bonferroni post hoc test was used to assess statistical significance. Changes with $p<0.05$ were considered to be significant. All data are presented as mean \pm SEM.

\section{Results}

\section{Cellular distribution of adenosine $A_{1}$ receptors in dorsal root ganglia and the spinal cord}

We first investigated the cellular distribution of $\mathrm{A}_{1} \mathrm{R}$ mRNA in DRGs and the spinal cord using fluorescent in situ hybridization. In DRGs, we detected abundant hybridization signals (Fig. 1a), which were seen primarily in neuronal somata. Cell counting revealed that $60.7 \pm 2.4 \%$ of DRG neurons express $A_{1} R$ mRNA. No hybridization signals were detected using a scramble control probe (Fig. 1b). To analyze the localization of $A_{1} R$ in DRG neuron subpopulations we combined in situ hybridization of $A_{1} R$ mRNA with immunostaining for established markers (Fig. 1c-f). Out of the $\mathrm{A}_{1} \mathrm{R}$-positive neurons, $26.4 \pm 2.9 \%$ coexpressed CGRP, 
Fig. 1 Distribution of adenosine $A_{1}$ receptors $\left(A_{1} R\right)$ in dorsal root ganglia (DRG). a Fluorescent in situ hybridization detected $\mathrm{A}_{1} \mathrm{R}$ mRNA in mouse DRGs. b No hybridization signal was detected using a scramble control probe. $\mathbf{c}-\mathbf{e}$ Fluorescent in situ hybridization of $A_{1} R$ mRNA combined with immunostaining of calcitonin gene-related peptide (CGRP; c), binding of isolectin B4 (IB4; d), or immunostaining of neurofilament-200 (NF200; e) revealed that $A_{1} R$ mRNA is expressed in populations of peptidergic and non-peptidergic $\mathrm{C}$ fibers and myelinated DRG neurons, respectively. f Quantitative summary of DRG neuron populations expressing $A_{1} R$ (2061 cells counted; $n=3$ animals). Scale bars: $100 \mu \mathrm{m}$ (a), $25 \mu \mathrm{m}$ (c)
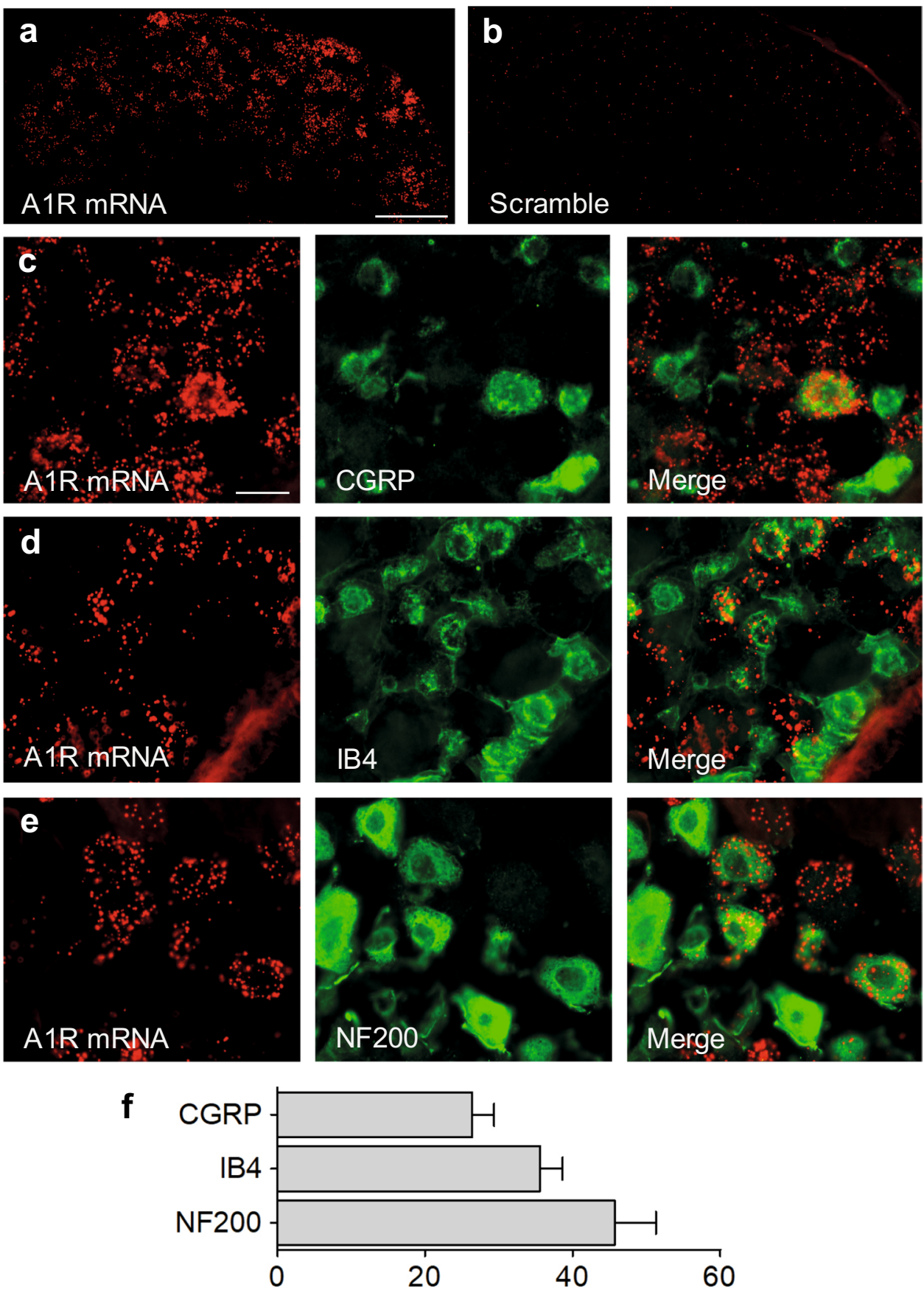

$A_{1} R$-expressing cells positive for marker (\%) a marker of peptidergic $\mathrm{C}$ fiber neurons, and $35.6 \pm 3.0 \%$ bound IB4, a marker of non-peptidergic $\mathrm{C}$ fiber neurons. Furthermore, $45.7 \pm 5.6 \%$ of $\mathrm{A}_{1} \mathrm{R}$-positive neurons coexpressed NF200, which stains myelinated DRG neurons. These data suggest that $A_{1} R$ are expressed in both unmyelinated and myelinated DRG neurons of naive mice.

In the spinal cord, $A_{1} R$ mRNA was enriched in cells of the dorsal horn (Fig. 2a). No specific hybridization signal was detected using scramble control, as expected
(Fig. 2b). Double-labeling in situ hybridization of $A_{1} R$ with the neuronal marker Rbfox 3 (which produces the 'neuronal nuclei' antigen NeuN) revealed that virtually all $\mathrm{A}_{1} \mathrm{R}$-positive cells co-express Rbfox3 (Fig. 2c), suggesting that $A_{1} R$ is mainly expressed in neurons in the dorsal horn of the spinal cord. Together, the expression of $A_{1} R$ in DRG neurons and dorsal horn neurons further supports its contribution to pain processing. 
Fig. 2 Distribution of adenosine $A_{1}$ receptors $\left(A_{1} R\right)$ in the spinal cord. a Fluorescent in situ hybridization detected $A_{1} R$ mRNA primarily in the dorsal horn of mouse spinal cord. b No hybridization signal was detected using a scramble control probe. c Doublelabeling in situ hybridization of $A_{1} R$ mRNA with mRNA of the neuronal marker Rbfox 3 in the dorsal horn shows that $A_{1} R$ is mainly expressed by neurons. Scale bars: $500 \mu \mathrm{m}$ (a), $50 \mu \mathrm{m}$ (c)
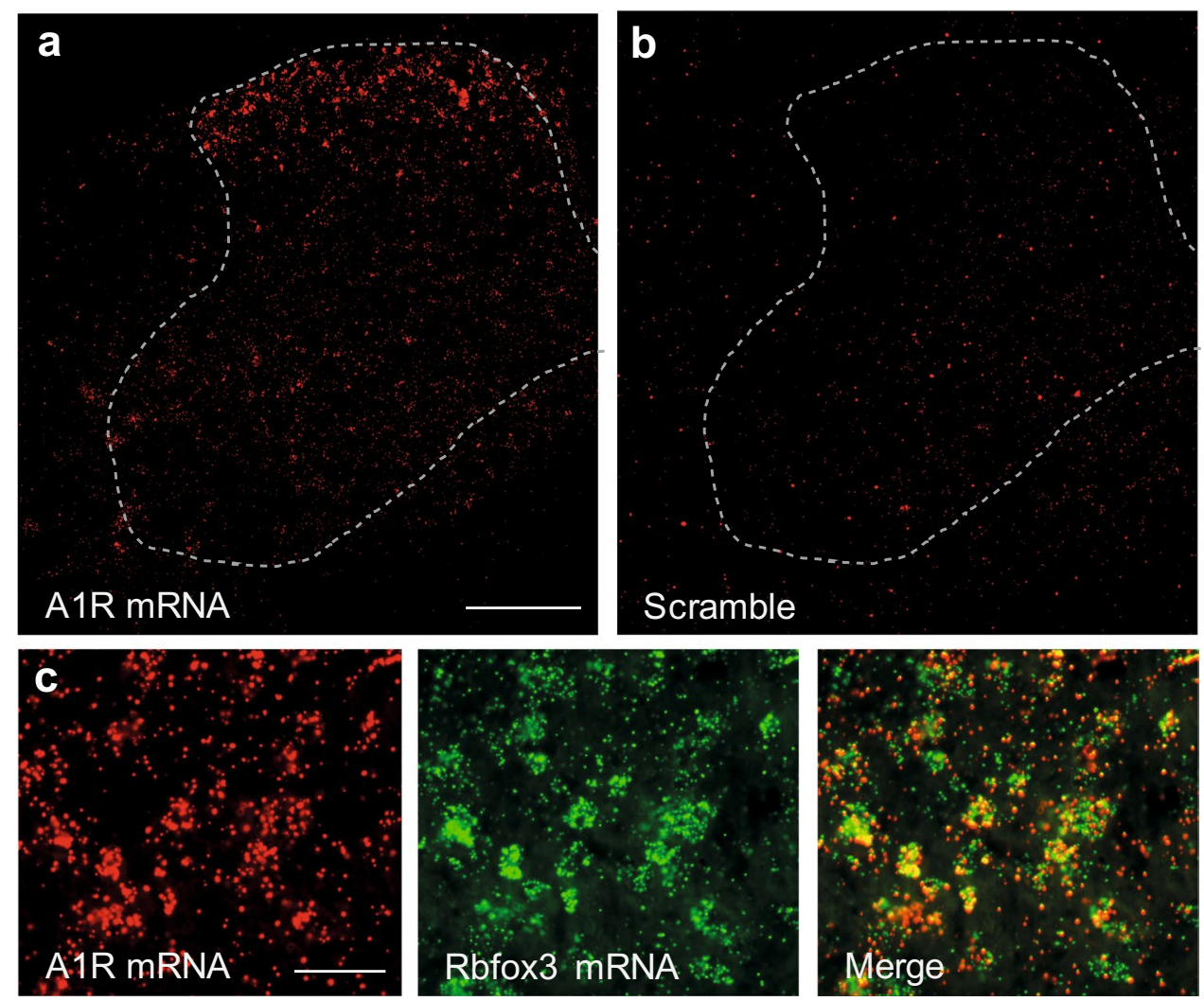

\section{Treatment with capadenoson does not affect neuropathic pain behavior in mice}

We next explored whether pharmacological activation of $\mathrm{A}_{1} \mathrm{R}$ might ameliorate neuropathic pain. For that purpose we tested whether treatment with the partial $A_{1} R$ agonist capadenoson affects mechanical hypersensitivity in two models of neuropathic pain in mice, i.e. the spared nerve injury (SNI) model of peripheral nerve injury and the paclitaxel model of chemotherapy-induced neuropathic pain. In a first set of experiments, we administered capadenoson perorally (p.o.) at three doses $(0.03,0.1$ and $0.3 \mathrm{mg} / \mathrm{kg})$. We chose these doses because capadenoson at $0.03,0.1$ and $0.3 \mathrm{mg} / \mathrm{kg}$ p.o. previously showed dose-dependent efficacy in a cardioprotection model in mice (personal communication from Cardiovascular Research, Bayer AG; data are not to be disclosed), and capadenoson at $0.3 \mathrm{mg} / \mathrm{kg}$ p.o. reduced overnight running distance on a running wheel in mice [18]. As shown in Fig. 3a, the SNI surgery induced a mechanical hypersensitivity of the affected hindpaw 13 days after SNI in all animals, as expected. One day thereafter, mice were p.o. treated with capadenoson, pregabalin or vehicle. However, treatment with capadenoson at all three doses did not significantly alter mechanical hypersensitivity over $24 \mathrm{~h}$ compared to the vehicle-treated group (Fig. 3a). By contrast, the positive control pregabalin $(60 \mathrm{mg} / \mathrm{kg}[23,27])$, significantly ameliorated the mechanical hypersensitivity, confirming that the SNI-induced neuropathic pain behavior is responsive to standard analgesic treatment.

We then investigated whether capadenoson treatment may inhibit chemotherapy-induced neuropathic pain in the paclitaxel model. Four i.p. injections of $1 \mathrm{mg} / \mathrm{kg}$ paclitaxel (on days 0, 2, 4 and 6) resulted in a significant mechanical hypersensitivity (determined 6 days after the last paclitaxel injection) in $43 \%$ of all paclitaxel-injected animals. One day thereafter, mice showing a significant mechanical hypersensitivity were p.o. treated with capadenoson $(0.03$, 0.1 and $0.3 \mathrm{mg} / \mathrm{kg}$ ), pregabalin $(60 \mathrm{mg} / \mathrm{kg}$ ), or vehicle. Similar to the SNI model, the delivery of capadenoson at three doses did not result in significant changes of paclitaxelinduced mechanical hypersensitivity as compared to vehicle (Fig. 3b). We observed a tendency of increased hypersensitivity after administration of $0.3 \mathrm{mg} / \mathrm{kg}$ capadenoson, which however was not significant. By contrast, treatment with pregabalin significantly inhibited the hypersensitivity (Fig. 3b). Together, these data suggest that treatment with the partial $\mathrm{A}_{1} \mathrm{R}$ agonist capadenoson at doses up to $0.3 \mathrm{mg} / \mathrm{kg}$ p.o. does not significantly affect neuropathic pain behavior in mice.

In a separate cohort of mice, we tested capadenoson at a higher dose (1 mg/kg p.o.) in the SNI model using the same experimental paradigm described above. After administration of this dose 14 days after SNI, the extent of SNIinduced mechanical hypersensitivity was slightly, but not significantly, ameliorated as compared to vehicle-treated 


\section{a SNI - p.o. delivery}

$\rightarrow 60 \mathrm{mg} / \mathrm{kg}$ Pregabalin

$\rightarrow 0.3 \mathrm{mg} / \mathrm{kg}$ Capadenoson

$\rightarrow 0.1 \mathrm{mg} / \mathrm{kg}$ Capadenoson

$\rightarrow 0.03 \mathrm{mg} / \mathrm{kg}$ Capadenoson

$\rightarrow$ Vehicle

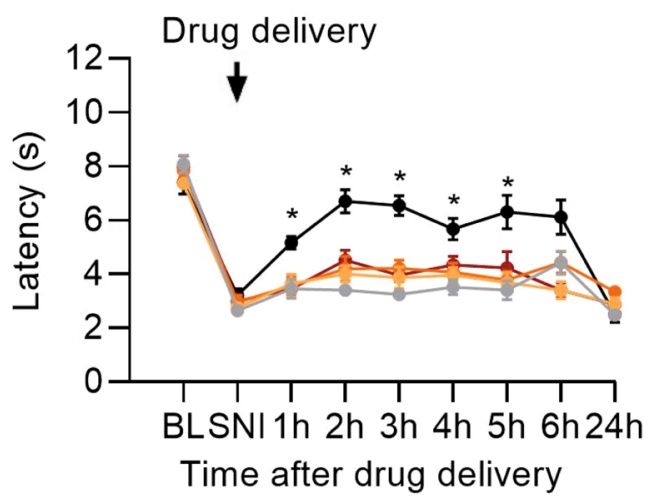

b Paclitaxel - p.o. delivery

$\rightarrow 60 \mathrm{mg} / \mathrm{kg}$ Pregabalin

$\rightarrow 0.3 \mathrm{mg} / \mathrm{kg}$ Capadenoson

$\rightarrow 0.1 \mathrm{mg} / \mathrm{kg}$ Capadenoson

$\because 0.03 \mathrm{mg} / \mathrm{kg}$ Capadenoson

$\rightarrow$ Vehicle

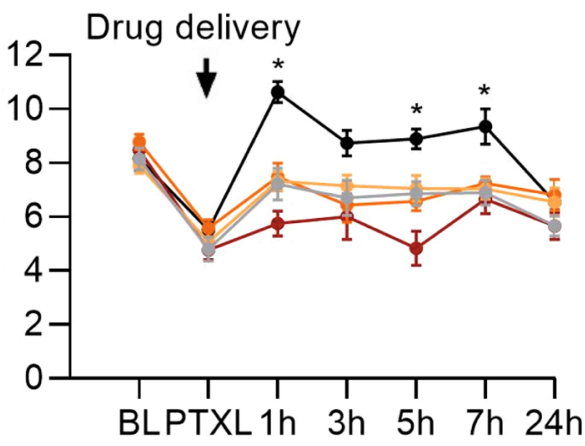

Time after drug delivery
C SNI - p.o. delivery
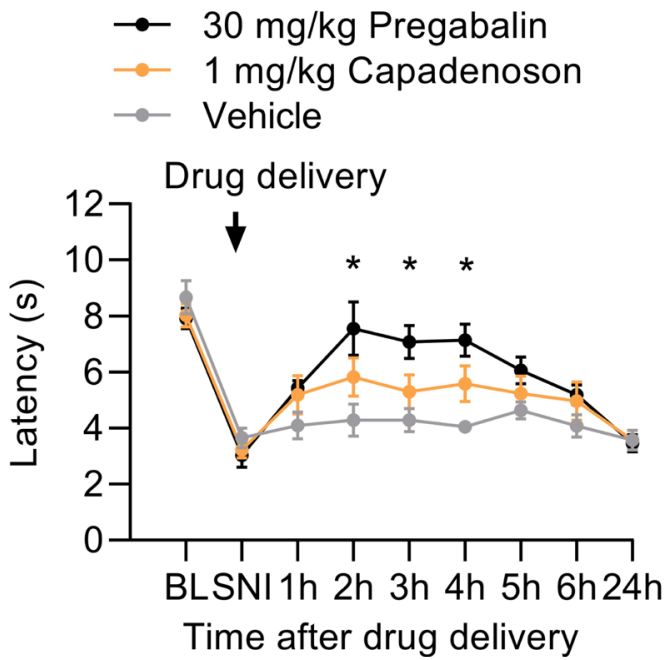

d SNI - i.v. delivery
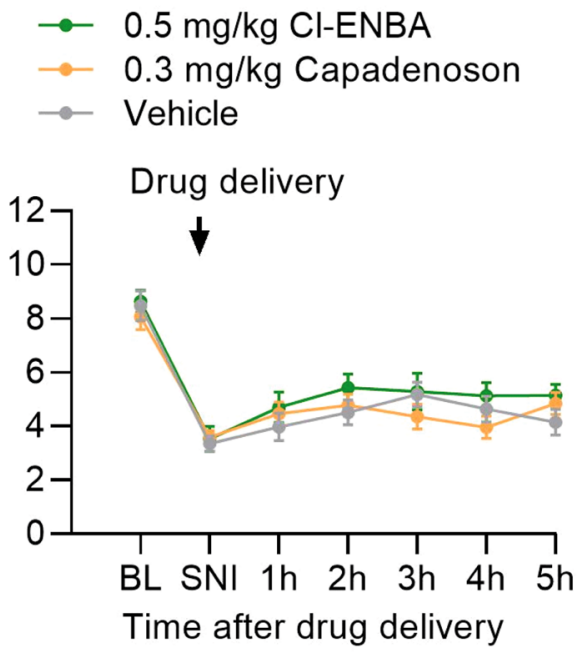

Fig. 3 Neuropathic pain behavior in mice is not affected by capadenoson treatment. a In the spared nerve injury (SNI) model, neuropathic pain was induced by surgery. Fourteen days thereafter, a mechanical hypersensitivity of the affected hindpaw (determined using a Dynamic Plantar Aesthesiometer) was detected in all mice. Then animals were orally treated with vehicle $(85 \%$ PEG400 / 15\% glycerol, $\mathrm{n}=13), 0.03 \mathrm{mg} / \mathrm{kg}$ capadenoson $(\mathrm{n}=13), 0.1 \mathrm{mg} / \mathrm{kg}$ capadenoson $(n=9), 0.3 \mathrm{mg} / \mathrm{kg}$ capadenoson $(n=12)$, or $60 \mathrm{mg} / \mathrm{kg}$ pregabalin $(n=12)$ and the mechanical sensitivity was assessed over $24 \mathrm{~h}$. Note that pregabalin inhibited the neuropathic pain behavior, whereas capadenoson was not effective. b In the paclitaxel model, neuropathic pain was induced by four i.p. injections of paclitaxel on day $0,2,4$ and 6. Seven days after the last paclitaxel injection, $43 \%$ of treated animals developed a significant mechanical hypersensitivity. These animals were orally treated with vehicle (85\% PEG400/15\% glycerol, $\mathrm{n}=11), 0.03 \mathrm{mg} / \mathrm{kg}$ capadenoson $(\mathrm{n}=13), 0.1 \mathrm{mg} / \mathrm{kg}$ capadenoson $(n=13), 0.3 \mathrm{mg} / \mathrm{kg}$ capadenoson $(n=12)$, or $60 \mathrm{mg} / \mathrm{kg}$ pregabalin $(\mathrm{n}=12)$ and the mechanical sensitivity was assessed over
$24 \mathrm{~h}$. Similar to the spared nerve injury model, pregabalin inhibited the paclitaxel-induced neuropathic pain behavior, whereas capadenoson was not effective. c-d In a separate cohort of mice, neuropathic pain was induced by SNI surgery. c At day 14 after SNI, the animals were orally treated with vehicle ( $85 \%$ PEG400/15\% glycerol; $n=11)$, $1 \mathrm{mg} / \mathrm{kg}$ capadenoson $(\mathrm{n}=11)$, or $30 \mathrm{mg} / \mathrm{kg}$ pregabalin $(\mathrm{n}=10)$, and the mechanical sensitivity was assessed over $24 \mathrm{~h}$. Pregabalin significantly inhibited the neuropathic pain behavior, whereas the effects of capadenoson were not significant. d At day 21 after SNI, the animals were i.v. treated by tail vein injection with vehicle (60\% PEAG400 in water; $\mathrm{n}=11), 0.3 \mathrm{mg} / \mathrm{kg}$ capadenoson $(\mathrm{n}=11)$, or $0.5 \mathrm{mg} / \mathrm{kg} \mathrm{Cl}$ ENBA $(n=10)$ and the mechanical sensitivity was assessed over $5 \mathrm{~h}$. Neither capadenoson nor Cl-ENBA did affect SNI-induced mechanical hypersensitivity. Data are presented as mean \pm SEM. $* p<0.05$, comparing drug treated and vehicle treated mice. Abbreviations used on the $\mathrm{x}$-axis: BL: baseline sensitivity in naive animals; SNI: spared nerve injury-induced hypersensitivity before drug delivery; PTXL: paclitaxel-induced hypersensitivity before drug delivery 
mice (Fig. 3c). By contrast, pregabalin, which in this experiment was given at $30 \mathrm{mg} / \mathrm{kg}$ p.o. [27], significantly inhibited the mechanical hypersensitivity in comparison to vehicle (Fig. 3c).

Finally, we assessed whether intravenous (i.v.) delivery of capadenoson affects SNI-induced mechanical hypersensitivity. For these experiments we used the same cohort of mice, but injected drugs 21 days after SNI (i.e., after a wash-out period of 7 days following the $1 \mathrm{mg} / \mathrm{kg}$ capadenoson p.o. measurements). We administered capadenoson at a dose of $0.3 \mathrm{mg} / \mathrm{kg}$ i.v. that significantly decreased infarct size in a model of acute myocardial infarction in rats [19]. As a control we used the full $\mathrm{A}_{1} \mathrm{R}$ agonist Cl-ENBA at a dose of $0.5 \mathrm{mg} / \mathrm{kg}$ that has been reported to inhibit SNI-induced mechanical allodynia in mice after i.p. delivery [28]. As shown in Fig. 3d, $0.3 \mathrm{mg} / \mathrm{kg}$ i.v. capadenoson did not affect SNI-induced mechanical hypersensitivity as compared to vehicle-treated animals. Unexpectedly, $0.5 \mathrm{mg} / \mathrm{kg}$ i.v. ClENBA also failed to alter the mechanical hypersensitivity (Fig. 3d; see also discussion). Moreover, all mice treated with Cl-ENBA displayed obvious sedative effects within the first 30-45 min after drug injection. Altogether, these behavioral experiments suggest that capadenoson is of limited value for the treatment of neuropathic pain.

\section{Capadenoson fails to affect potassium currents in dissociated DRG neurons}

We next assessed whether capadenoson affects electrophysiological properties of DRG neurons. Because coupling of $\mathrm{A}_{1} \mathrm{R}$ to neuronal potassium channels has been considered as a mechanism contributing to the analgesic activity of $A_{1} R$ agonists [29-31], we analyzed outward potassium currents $\left(\mathrm{I}_{\mathrm{K}}\right)$ of dissociated DRG neurons in presence of capadenoson. In particular, we assessed the transient, peak current component and the sustained, steady-state current component of $\mathrm{I}_{\mathrm{K}}[32,33]$. Whole-cell patch-clamp recordings were performed at a holding potential of $-70 \mathrm{mV}$ by applying a 1000 -ms-long prepulse of $-100 \mathrm{mV}$ followed by series of 500 -ms-long pulses ranging from -100 to $+120 \mathrm{mV}$ in intervals of $20 \mathrm{mV}$. As shown in Fig. 4, addition of capadenoson $(100 \mathrm{nM})$ to the external solution did neither affect $\mathrm{I}_{\mathrm{K}}$ peak currents (Fig. 4a) nor $\mathrm{I}_{\mathrm{K}}$ steady-state currents (Fig. 4b). An original registration at $+100 \mathrm{mV}$ is depicted in Fig. 4c. The $I_{K}$ peak currents were also not affected by the full $A_{1} R$ agonist CPA (100 nM [13]; Fig. 4d). However, $\mathrm{I}_{\mathrm{K}}$ steady-state currents were significantly reduced by CPA (Fig. 4e and 4f), pointing to a coupling of $\mathrm{A}_{1} \mathrm{R}$ and potassium channels in DRG neurons. The lack of effect of capadenoson in these experiments further supports the finding that pharmacological intervention with this partial $A_{1} R$ agonist might not be a valuable approach for the treatment of pain.

\section{Discussion}

In this study, we investigated whether the partial $\mathrm{A}_{1} \mathrm{R}$ agonist capadenoson might be sufficient for treatment of neuropathic pain. Even though $A_{1} R$ is localized to DRG neurons and dorsal horn neurons, which are relevant for pain processing, capadenoson did not affect the pain behavior induced by peripheral nerve injury and chemotherapy, and it did not alter potassium currents in DRG neurons. Hence, capadenoson seems not to be suitable for neuropathic pain therapy.

The distribution of $A_{1} R$ in the nociceptive system has been investigated in earlier studies, however with conflicting results. In immunostaining experiments it was reported that $\mathrm{A}_{1} \mathrm{R}$ immunoreactivity is present in a subset of rat DRG neurons [10], and double-labeling experiments suggested that about $32 \%, 80 \%$ and $1 \%$ of $A_{1} R$-positive rat DRG neurons co-express substance P, IB4 and NF200, respectively [11]. We here performed in situ hybridization experiments and confirmed $\mathrm{A}_{1} \mathrm{R}$ expression in a subset of mouse DRG neurons. However, our in situ hybridization combined with immunostaining revealed that $\mathrm{A}_{1} \mathrm{R}$ mRNA is expressed in $26 \%, 36 \%$ and $46 \%$ of neurons positive for CGRP, IB4 and NF200, respectively. Species differences in the distribution of $A_{1} R$ in DRG neurons of rats and mice, differences between protein and mRNA expression, or a lack of antibody specificity might account for this apparent discrepancy.

In the spinal cord, we found $A_{1} R$ mRNA to be enriched in dorsal horn neurons. This observation is in accordance with previous autoradiography experiments on rat spinal cord sections, in which $\mathrm{A}_{1} \mathrm{R}$ were detected predominantly in the superficial dorsal horn [34-36]. Immunohistochemical analyses of rat spinal cord sections were less consistent, because some studies showed a dense band of staining predominantly in lamina II of the dorsal horn [10, 12], whereas more diffuse $A_{1} R$ immunoreactivity throughout the spinal cord were observed in another study [13]. Hence, our in situ hybridization data add confidence that the major localization of $\mathrm{A}_{1} \mathrm{R}$ mRNA in the spinal cord are interneurons in the dorsal horn. It should be noted however that $A_{1} R$ has been detected in activated microglia cells after induction of neuropathic pain [37], and that delivery of an $\mathrm{A}_{1} \mathrm{R}$ agonist ameliorated the injury-induced microglia activation and neuronal sensitization [28]. Moreover, $A_{1} R$ are expressed in various supraspinal CNS regions including brain cortex, hippocampus, and cerebellum [9], which was however not investigated in this study.

Early preclinical studies in the 1980s with systemic and intrathecal administration of adenosine, $A_{1} R$ agonists and $A_{1} R$ antagonists suggested that targeting $A_{1} R$ might be suitable for treatment of neuropathic pain (for review, see 


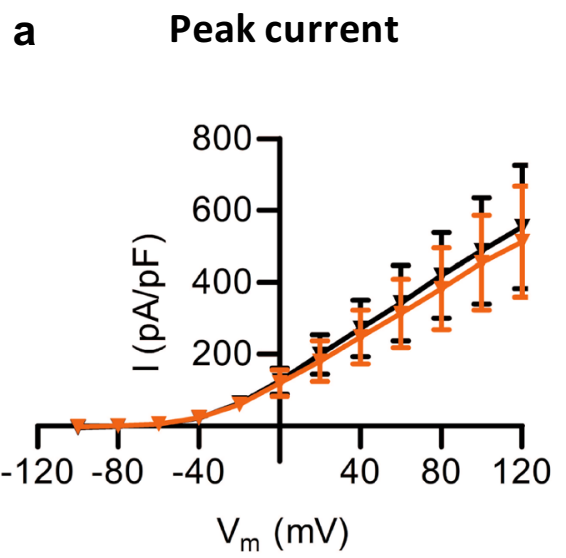

d

Peak current

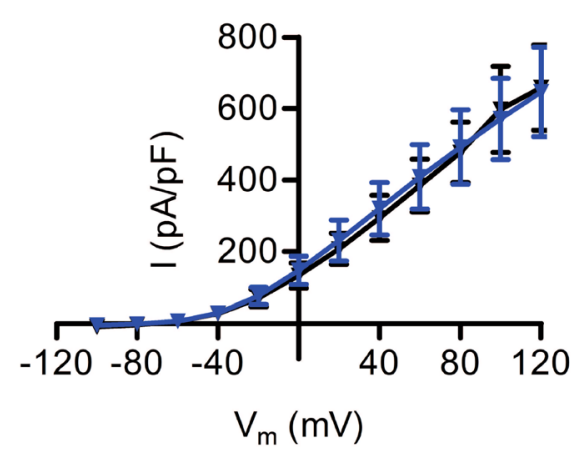

b Steady-state current

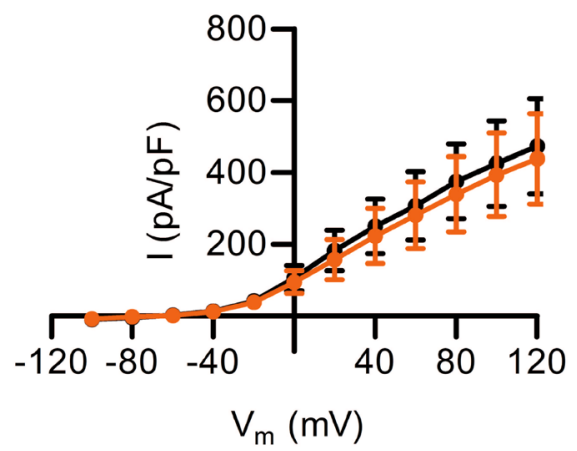

e Steady-state current

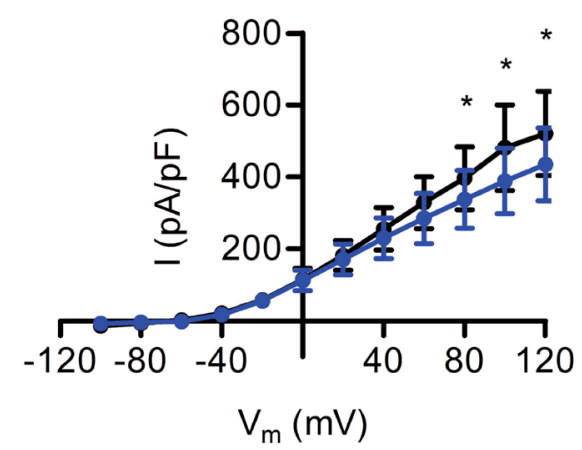

C

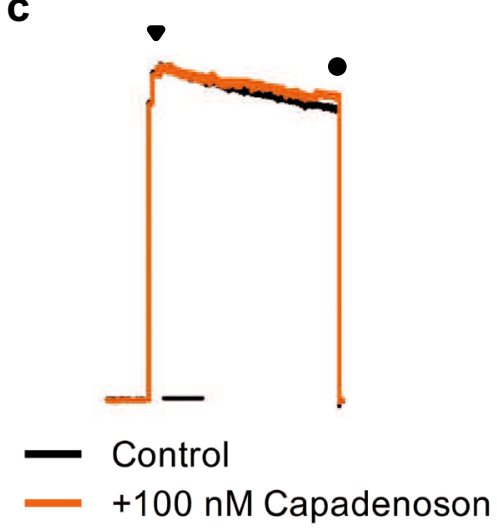

Fig. 4 Potassium currents in DRG neurons are not affected by capadenoson. IV relations of the total potassium currents $\left(\mathrm{I}_{\mathrm{K}}\right)$ were measured in isolated lumbar DRG neurons of mice using the whole cell patch-clamp technique. After the measurement of the control current, the partial $A_{1} R$ agonist capadenoson $(100 \mathrm{nM} ; \mathrm{n}=4 ; \mathbf{a}-\mathbf{c})$ or the full $\mathrm{A}_{1} \mathrm{R}$ agonist $\mathrm{N}^{6}$-cyclopentyladenosine $(\mathrm{CPA} ; 100 \mathrm{nM} ; \mathrm{n}=5$; d-f) were added into the bath solution. Ten minutes thereafter, cur- rents were measured again. Original registrations at $+100 \mathrm{mV}$ are presented in $\mathbf{c}$ and $\mathbf{f}$ and indicate the peak current component (marked by a triangle) and the steady-state current component (marked by a circle). Capadenoson failed to affect both the peak and steady-state currents. CPA did not affect the peak current but significantly reduced the steady-state current. Data are presented as mean \pm SEM, *p $<0.05$

of peripheral nerve injury [42]. However, CCPA seems not to be suitable for systemic treatment as it reduced the latency to fall off the rotarod and caused catalepsy-like behavior in a dose-dependent manner [43]. Hence, the usefulness of systemic $A_{1} R$ agonists is limited by unwanted cardiovascular, motor and sedative side effects.

In general, improved efficacy of $A_{1} R$ agonists for pain treatment might be reached with allosteric modulators or partial agonists [7, 31, 44, 45]. Among the allosteric $\mathrm{A}_{1} \mathrm{R}$ modulators that have been tested for analgesia in vivo are T62 and TRR469. Oral administration of T62 reduced mechanical allodynia after peripheral nerve injury in rats. However, within 5 days of repeated daily administration, a tolerance occurred that led to decreased analgesic efficacy over time partly as a result of receptor down-regulation [46, 47]. T62 was also subjected to a clinical trial in patients with postherpetic neuralgia, which however 
was discontinued $[9,45]$. Intraperitoneal administration of TRR469, a more potent allosteric $\mathrm{A}_{1} \mathrm{R}$ modulator as compared to T62, inhibited neuropathic pain in the model of streptozotocin-induced diabetic neuropathy and did not display locomotor or cataleptic side effects in mice [43]. Hence, there are obvious discrepancies on the effectiveness and tolerability of $\mathrm{A}_{1} \mathrm{R}$ agonists reported in different studies, probably due to the use of different compounds, routes of administration and models of neuropathic pain.

Another strategy to separate the desired from undesired pharmacological effects is to use partial $\mathrm{A}_{1} \mathrm{R}$ agonists. These compounds have been shown to activate only certain responses of $A_{1} R$-mediated G-protein signaling, mostly in cells with high receptor reserve [48]. Moreover, the partial agonism is postulated to achieve conformational selection of a distinct active state, as recently shown for $A_{2 A} R$ [49]. Hence, partial agonists might show better receptor selectivity due to increased receptor density and/or efficiency of receptor coupling to effector systems in the presence of nerve injury $[7,50,51]$. We here tested the partial $\mathrm{A}_{1} \mathrm{R}$ agonist capadenoson in two animal models of neuropathic pain. Capadenoson, which previously entered into two phase IIa clinical trials in patients with atrial fibrillation and stable angina, has been reported to have beneficial cardiovascular effects [19, 52, 53]. Unexpectedly, in our behavior experiments, four different doses of p.o. administered capadenoson (0.03, 0.1, 0.3 and $1 \mathrm{mg} /$ $\mathrm{kg})$ and one dose of i.v. delivered capadenoson $(0.3 \mathrm{mg} /$ $\mathrm{kg}$ ) failed to significantly inhibit mechanical hypersensitivity in neuropathic pain models. In a previous study, p.o. administration of capadenoson at 0.3 and $1 \mathrm{mg} / \mathrm{kg}$ in mice led to a significant decrease of locomotion activity in a running wheel model as a surrogate marker for sedative CNS effects, and capadenoson at $1 \mathrm{mg} / \mathrm{kg}$ substantially decreased the running distance in this model by $37 \%$ [18]. We observed a trend towards inhibition of neuropathic pain behavior (not significant) at a dose of $1 \mathrm{mg} / \mathrm{kg}$ p.o. capadenoson in the SNI model. However, the profound impairment of running wheel behavior [18] indicates that this dose is associated with sedative adverse effects. Thus, we did not test higher doses of p.o. administered capadenoson in our study. Instead thereof, we assessed i.v. delivery of capadenoson at $0.3 \mathrm{mg} / \mathrm{kg}$, but again did not observe any inhibition of neuropathic pain behavior. By contrast, capadenoson at 0.1 and $0.3 \mathrm{mg} / \mathrm{kg}$ i.v. has been reported to decrease infarct size in a model of acute myocardial infarction in rats [19]. Considering that capadenoson in the dose range of $0.3-1 \mathrm{mg} / \mathrm{kg}$ p.o. and $0.1-0.3 \mathrm{mg} / \mathrm{kg}$ i.v. provided significant pharmacological activity in other models $[18,19]$ we conclude that partial $A_{1} R$ agonism is of minor value for treatment of neuropathic pain. It should be noted however that in a recent study, capadenoson was found to have also activity at $\mathrm{A}_{2 \mathrm{~B}} \mathrm{R}$ [54]. As $\mathrm{A}_{2 \mathrm{~B}} \mathrm{R}$ agonists exhibit proinflammatory effects on immune cells [7], this might also affect the pain behavior after nerve injury or chemotherapy.

About the reasons for the ineffectiveness of the full $A_{1} R$ agonist Cl-ENBA in the SNI model we can only speculate. We intended to use $0.5 \mathrm{mg} / \mathrm{kg} \mathrm{Cl}$-ENBA as a positive control in our experiment with i.v. administered capadenoson, because Luongo and colleagues [28] reported that this dose significantly reduced neuropathic pain behavior after SNI. It has to be considered that Luongo et al. used a modified version of the SNI model, in which the tibial nerve is left intact [55], and not the sural nerve as in our study. Moreover, in the study by Luongo et al. Cl-ENBA was i.p. administered 7 days post injury and mechanical hypersensitivity was assessed with a dynamic plantar aesthesiometer using a ramp of $3 \mathrm{~g} / \mathrm{s}$ [28], whereas we delivered Cl-ENBA i.v. 21 days post injury and used a ramp of $0.5 \mathrm{~g} / \mathrm{s}$. Although speculative, these differences in experimental settings might account for the discrepancies between the study of Luongo et al. and our findings.

The lack of efficacy of capadenoson for analgesia is also supported by our patch-clamp experiments, in which capadenoson failed to affect potassium currents in dissociated mouse DRG neurons. Various downstream mechanisms of $A_{1} R$ have been previously identified in different tissues including cAMP/PKA and PLC/IP ${ }_{3} / \mathrm{DAG}$ signaling, potassium channel stimulation, calcium channel inhibition, and $\beta$-arrestin mediated receptor modulation (for review, see [7]). In rat ventricular myocytes, $A_{1} R$ are coupled to potassium channels by $G$ protein signaling [56], and we thus speculated that a coupling of $\mathrm{A}_{1} \mathrm{R}$ and potassium channels might also exist in DRG neurons. Indeed, in our patch-clamp experiments addition of the full $\mathrm{A}_{1} \mathrm{R}$ agonist CPA significantly decreased the steady-state potassium currents at positive voltage ranges. By contrast, the peak potassium currents were not altered, suggesting a specific inhibition of the sustained current component. In previous studies, adenosine and the full $\mathrm{A}_{1} \mathrm{R}$ agonist CCPA inhibited potassium currents by a steady-state block in AZF cells [33], and inhibition of sustained potassium currents by tetraethylammonium prolonged the duration of the repolarization phase and thereby reduced intrinsic firing in trigeminal neurons [32]. Accordingly, CPA has been shown to inhibit action potentials [57] and A- and C-fiber evoked field potentials [41] in neuronal tissues. Hence, we hypothesize that a decrease of the steady-state potassium current by CPA might lead to a reduced firing frequency in DRG neurons and inhibition of pain processing. However, in contrast to CPA, capadenoson did not affect the steadystate potassium currents in DRG neurons.

Altogether, in our study, a partial $A_{1} R$ agonist failed to ameliorate neuropathic pain in mice. If this holds true in other species or humans has to be shown. 
Acknowledgements We are grateful to Cyntia Schäfer for excellent technical assistance. This study was supported by the Grants4Indications ${ }^{\mathrm{TM}}$ initiative of Bayer AG, Leverkusen, Germany, and by European Regional Development Fund/LeitmarktAgentur.NRW (EFRE-0800971/LS-1-2-023d). The funding sources had no role in study design; the collection, analysis, and interpretation of data; or the writing of the manuscript and the decision to publish.

Author contribution Achim Schmidtko designed and supervised the experiments. Katharina Metzner, Tilman Gross, Annika Balzulat, Gesine Wack, and Ruirui Lu conducted the experiments. Katharina Metzner and Achim Schmidtko analyzed the data and wrote the manuscript. All authors discussed the results and commented on the manuscript.

Funding Open Access funding enabled and organized by Projekt DEAL. This study was supported by the Grants4Indications ${ }^{\mathrm{TM}}$ initiative of Bayer AG, Leverkusen, Germany, and by European Regional Development Fund/LeitmarktAgentur.NRW (EFRE-0800971/LS-1-2023d). The funding sources had no role in study design; the collection, analysis, and interpretation of data; or the writing of the manuscript and the decision to publish.

Data availability The datasets generated during and/or analyzed during the current study are available from the corresponding author on reasonable request.

Code availability Not applicable.

\section{Declarations}

Ethics approval All experiments were ethically reviewed and approved by our local Ethics Committee for Animal Research (Regierungspräsidium Darmstadt, Germany).

Consent to participate Not applicable.

Consent for publication Not applicable.

Conflicts of interest Katharina Metzner declares no conflict of interest. Tilman Groß declares no conflict of interest.

Annika Balzulat declares no conflict of interest.

Gesine Wack declares no conflict of interest.

Ruirui $\mathrm{Lu}$ declares no conflict of interest.

Achim Schmidtko declares no conflict of interest.

Open Access This article is licensed under a Creative Commons Attribution 4.0 International License, which permits use, sharing, adaptation, distribution and reproduction in any medium or format, as long as you give appropriate credit to the original author(s) and the source, provide a link to the Creative Commons licence, and indicate if changes were made. The images or other third party material in this article are included in the article's Creative Commons licence, unless indicated otherwise in a credit line to the material. If material is not included in the article's Creative Commons licence and your intended use is not permitted by statutory regulation or exceeds the permitted use, you will need to obtain permission directly from the copyright holder. To view a copy of this licence, visit http://creativecommons.org/licenses/by/4.0/.

\section{References}

1. van Hecke O, Austin SK, Khan RA et al (2014) Neuropathic pain in the general population: a systematic review of epidemiological studies. Pain 155:654-662. https://doi.org/10.1016/j.pain.2013. 11.013

2. Yekkirala AS, Roberson DP, Bean BP et al (2017) Breaking barriers to novel analgesic drug development. Nat Rev Drug Discov 16:545-564. https://doi.org/10.1038/nrd.2017.87

3. Woolf CJ (2020) Capturing novel non-opioid pain targets. Biol Psychiat 87:74-81. https://doi.org/10.1016/j.biopsych.2019.06. 017

4. Finnerup NB, Attal N, Haroutounian S et al (2015) Pharmacotherapy for neuropathic pain in adults: a systematic review and meta-analysis. Lancet Neurol 14:162-173

5. Basbaum AI, Bautista DM, Scherrer G et al (2009) Cellular and molecular mechanisms of pain. Cell 139:267-284. https://doi.org/ 10.1016/j.cell.2009.09.028

6. Colloca L, Ludman T, Bouhassira D et al (2017) Neuropathic pain Nat Rev Dis Primers 3:2220. https://doi.org/10.1038/nrdp.2017.2

7. Sawynok J (2016) Adenosine receptor targets for pain. Neuroscience 338:1-18. https://doi.org/10.1016/j.neuroscience.2015.10. 031

8. Adebiyi MG, Manalo J, Kellems RE et al (2019) Differential role of adenosine signaling cascade in acute and chronic pain. Neurosci Lett 712:134483. https://doi.org/10.1016/j.neulet.2019.134483

9. Borea PA, Gessi S, Merighi S et al (2018) Pharmacology of adenosine receptors: the state of the art. Physiol Rev 98:1591-1625. https://doi.org/10.1152/physrev.00049.2017

10. Schulte G, Robertson B, Fredholm B et al (2003) Distribution of antinociceptive adenosine A1 receptors in the spinal cord dorsal horn, and relationship to primary afferents and neuronal subpopulations. Neuroscience 121:907-916. https://doi.org/10. 1016/S0306-4522(03)00480-9

11. Lima FO, Souza GR, Verri WA, JR et al. (2010) Direct blockade of inflammatory hypernociception by peripheral A1 adenosine receptors: involvement of the NO/cGMP/PKG/KATP signaling pathway. Pain 151:506-515. https://doi.org/10.1016/j.pain.2010. 08.014

12. Ackley MA, Governo RJM, Cass CE et al (2003) Control of glutamatergic neurotransmission in the rat spinal dorsal horn by the nucleoside transporter ENT1. J Physiol 548:507-517. https://doi. org/10.1113/jphysiol.2002.038091

13. Deuchars SA, Brooke RE, Deuchars J (2001) Adenosine A1 receptors rreduce release from excitatory but not inhibitory synaptic inputs onto lateral horn neurons. J Neurosci 21:6308-6320. https://doi.org/10.1523/JNEUROSCI.21-16-06308.2001

14. Wu W-P, Hao J-X, Halldner L et al (2005) Increased nociceptive response in mice lacking the adenosine A1 receptor. Pain 113:395-404. https://doi.org/10.1016/j.pain.2004.11.020

15. Zylka MJ, Sowa NA, Taylor-Blake B et al (2008) Prostatic acid phosphatase is an ectonucleotidase and suppresses pain by generating adenosine. Neuron 60:111-122. https://doi.org/10.1016/j. neuron.2008.08.024

16. Sowa NA, Voss MK, Zylka MJ (2010) Recombinant ecto-5'Nucleotidase (CD73) has long lasting antinociceptive effects that are dependent on adenosine A1 receptor activation. Mol. Pain 6:1744-8069-6-20. https://doi.org/10.1186/1744-8069-6-20

17. Korboukh I, Hull-Ryde EA, Rittiner JE et al (2012) Orally active adenosine A1 receptor agonists with antinociceptive effects in mice. J Med Chem 55:6467-6477. https://doi.org/10.1021/jm300 4834

18. Meibom D, Albrecht-Küpper B, Diedrichs N et al (2017) Neladenoson bialanate hydrochloride: a prodrug of a partial adenosine A1 receptor agonist for the chronic treatment of heart diseases. 
ChemMedChem 12:728-737. https://doi.org/10.1002/cmdc.20170 0151

19. Albrecht-Kupper BE, Leineweber K, Nell PG (2012) Partial adenosine A1 receptor agonists for cardiovascular therapies. Purinergic Signal 8:91-99. https://doi.org/10.1007/s11302-011-9274-3

20. Decosterd I, Woolf CJ (2000) Spared nerve injury: an animal model of persistent peripheral neuropathic pain. Pain 87:149-158. https://doi.org/10.1016/S0304-3959(00)00276-1

21. Smith SB, Crager SE, Mogil JS (2004) Paclitaxel-induced neuropathic hypersensitivity in mice: Responses in 10 inbred mouse strains. Life Sci 74:2593-2604. https://doi.org/10.1016/j.lfs.2004. 01.002

22. Alessandri-Haber N, Dina OA, Joseph EK et al (2008) Interaction of transient receptor potential vanilloid 4, integrin, and Src tyrosine kinase in mechanical hyperalgesia. J Neurosci 28:1046-1057. https://doi.org/10.1523/JNEUROSCI.4497-07.2008

23. Lu R, Bausch AE, Kallenborn-Gerhardt W et al (2015) Slack channels expressed in sensory neurons control neuropathic pain in mice. J Neurosci 35:1125-1135. https://doi.org/10.1523/JNEUR OSCI.2423-14.2015

24. Schmidtko A, Gao W, Konig P et al (2008) cGMP produced by NO-sensitive guanylyl cyclase essentially contributes to inflammatory and neuropathic pain by using targets different from cGMP-dependent protein kinase I. J Neurosci 28:8568-8576. https://doi.org/10.1523/JNEUROSCI.2128-08.2008

25. Heine S, Michalakis S, Kallenborn-Gerhardt W et al (2011) CNGA3: a target of spinal nitric oxide/cGMP signaling and modulator of inflammatory pain hypersensitivity. J Neurosci 31:11184 11192. https://doi.org/10.1523/JNEUROSCI.6159-10.2011

26. Petersen J, Mergia E, Kennel L et al (2019) Distinct functions of soluble guanylyl cyclase isoforms NO-GC1 and NO-GC2 in inflammatory and neuropathic pain processing. Pain 160:607-618. https://doi.org/10.1097/j.pain.0000000000001440

27. Leksiri S, Hasriadi, Dasuni Wasana PW et al. (2020) Co-administration of pregabalin and curcumin synergistically decreases pain-like behaviors in acute nociceptive pain murine models. Molecules 25. https://doi.org/10.3390/molecules25184172

28. Luongo L, Petrelli R, Gatta L et al (2012) 5'-Chloro-5'-deoxy$( \pm)$-ENBA, a potent and selective adenosine A1 receptor agonist, alleviates neuropathic pain in mice through functional glial and microglial changes without affecting motor or cardiovascular functions. Molecules 17:13712-13726. https://doi.org/10.3390/ molecules 171213712

29. Trussell LO, Jackson MB (1985) Adenosine-activated potassium conductance in cultured striatal neurons. PNAS 82:4857-4861. https://doi.org/10.1073/pnas.82.14.4857

30. Varani K, Vincenzi F, Merighi S et al. (2017) Biochemical and pharmacological role of A1 adenosine receptors and their modulation as novel therapeutic strategy. Protein Reviews 1051. https:// doi.org/10.1007/5584_2017_61

31. Magni G, Ceruti S (2019) The role of adenosine and P2Y receptors expressed by multiple cell types in pain transmission. Brain Res Bull 151:132-143. https://doi.org/10.1016/j.brainresbull. 2019.02.011

32. Yoshida S, Takahashi M, Kadoi J et al (2007) The functional difference between transient and sustained $\mathrm{K}+$ currents on the action potentials in tetrodotoxin-resistant adult rat trigeminal ganglion neurons. Brain Res 1152:64-74. https://doi.org/10.1016/j.brain res.2007.03.039

33. Xu L, Enyeart JJ (1999) Adenosine inhibits a non-inactivating K+ current in bovine adrenal cortical cells by activation of multiple P1 receptors. J Physiology 521(Pt 1):81-97. https://doi.org/10. 1111/j.1469-7793.1999.00081.x

34. Geiger JD, LaBella FS, Nagy JI (1984) Characterization and localization of adenosine receptors in rat spinal cord. J Neurosci
4:2303-2310. https://doi.org/10.1523/JNEUROSCI.04-09-02303. 1984

35. Choca JI, Green RD, Proudfit HK (1988) Adenosine A1 and A2 receptors of the substantia gelatinosa are located predominantly on intrinsic neurons: an autoradiography study. J Pharmacol Exp Ther 247:757

36. Bantel CM, Childers SRP, Eisenach JCM (2002) Role of adenosine receptors in spinal G-protein activation after peripheral nerve injury. Anesthesiology 96:1443-1449

37. Luongo L, Guida F, Imperatore R et al (2014) The A1 adenosine receptor as a new player in microglia physiology. Glia 62:122132. https://doi.org/10.1002/glia.22592

38. Sawynok J (1998) Adenosine receptor activation and nociception. Eur J Pharmacol 347:1-11. https://doi.org/10.1016/S00142999(97)01605-1

39. Dickenson AH, Suzuki R, Reeve AJ (2000) Adenosine as a potential analgesic target in inflammatory and neuropathic pains. CNS Drugs 13:77-85. https://doi.org/10.2165/00023 210-200013020-00001

40. Curros-Criado MM, Herrero JF (2005) The antinociceptive effects of the systemic adenosine A1 receptor agonist CPA in the absence and in the presence of spinal cord sensitization. Pharmacol Biochem Behav 82:721-726. https://doi.org/10. 1016/j.pbb.2005.11.014

41. Gong Q-J, Li Y-Y, Xin W-J et al (2010) Differential effects of adenosine $\mathrm{A} 1$ receptor on pain-related behavior in normal and nerve-injured rats. Brain Res 1361:23-30. https://doi.org/10. 1016/j.brainres.2010.09.034

42. Goldman N, Chen M, Fujita T et al (2010) Adenosine A1 receptors mediate local anti-nociceptive effects of acupuncture. Nat Neurosci 13:883-888. https://doi.org/10.1038/nn.2562

43. Vincenzi F, Targa M, Romagnoli R et al (2014) TRR469, a potent A1 adenosine receptor allosteric modulator, exhibits antinociceptive properties in acute and neuropathic pain models in mice. Neuropharmacology 81:6-14. https://doi.org/10.1016/j. neuropharm.2014.01.028

44. Petrelli R, Torquati I, Kachler S et al (2015) 5'-C-Ethyltetrazolyl-N6-substituted adenosine and 2-Chloro-adenosine derivatives as highly potent dual acting $\mathrm{A} 1$ adenosine receptor agonists and A3 adenosine receptor antagonists. J Med Chem 58:2560-2566. https://doi.org/10.1021/acs.jmedchem.5b00074

45. Deb PK (2019) Therapeutic potentials of adenosine receptors: the state of the art. Curr Pharm Des 25:2789-2791. https://doi. org/10.2174/138161282526191007143942

46. Li X, Conklin D, Ma W et al (2002) Spinal noradrenergic activation mediates allodynia reduction from an allosteric adenosine modulator in a rat model of neuropathic pain. Pain 97:117-125. https://doi.org/10.1016/S0304-3959(02)00011-8

47. Li XP, Bantel CM, Conklin DB et al (2004) Repeated dosing with oral allosteric modulator of adenosine A1 receptor produces tolerance in rats with neuropathic pain. Anesthesiology 100:956-961

48. Srinivas M, Shryock JC, Dennis DM et al (1997) Differential A1 adenosine receptor reserve for two actions of adenosine on guinea pig atrial myocytes. Mol Pharmacol 52:683-691. https://doi.org/ 10.1124/mol.52.4.683

49. Ye L, van Eps N, Zimmer M et al (2016) Activation of the A2A adenosine G-protein-coupled receptor by conformational selection. Nature 533:265-268. https://doi.org/10.1038/nature17668

50. Schaddelee MP, Collins SD, DeJongh J et al (2005) Pharmacokinetic/pharmacodynamic modelling of the anti-hyperalgesic and anti-nociceptive effect of adenosine A1 receptor partial agonists in neuropathic pain. Eur J Pharmacol 514:131-140. https://doi. org/10.1016/j.ejphar.2005.03.026

51. Magni G, Riccio D, Ceruti S (2018) Tackling chronic pain and inflammation through the purinergic system. Curr Med Chem 
25:3830-3865. https://doi.org/10.2174/09298673246661707101 10630

52. Tendera M, Gaszewska-Zurek E, Parma Z et al (2012) The new oral adenosine A1 receptor agonist capadenoson in male patients with stable angina. Clin Res Cardiol 101:585-591. https://doi.org/ 10.1007/s00392-012-0430-8

53. Sabbah HN, Gupta RC, Kohli S et al (2013) Chronic therapy with a partial adenosine A1 receptor agonist improves left ventricular function and remodeling in dogs with advanced heart failure. Circ Heart Fail 6:563-571. https://doi.org/10.1161/CIRCHEARTF AILURE.112.000208

54. Baltos J-A, Vecchio EA, Harris MA et al (2017) Capadenoson, a clinically trialed partial adenosine A1 receptor agonist, can stimulate adenosine A2B receptor biased agonism. Biochem Pharmacol 135:79-89. https://doi.org/10.1016/j.bcp.2017.03.014

55. Shields SD, Eckert WA, Basbaum AI (2003) Spared nerve injury model of neuropathic pain in the mouse: a behavioral and anatomic analysis. J Pain 4:465-470. https://doi.org/10.1067/S15265900(03)00781-8

56. Kirsch GE, Codina J, Birnbaumer L et al (1990) Coupling of ATP-sensitive $\mathrm{K}+$ channels to A1 receptors by $\mathrm{G}$ proteins in rat ventricular myocytes. Am J Physiol 259:H820-H826. https://doi. org/10.1152/ajpheart.1990.259.3.H820
57. Hargus NJ, Bertram EH, Patel MK (2009) Adenosine A1 receptors presynaptically modulate excitatory synaptic input onto subiculum neurons. Brain Res 1280:60-68. https://doi.org/10.1016/j.brainres. 2009.05.027

Publisher's note Springer Nature remains neutral with regard to jurisdictional claims in published maps and institutional affiliations.

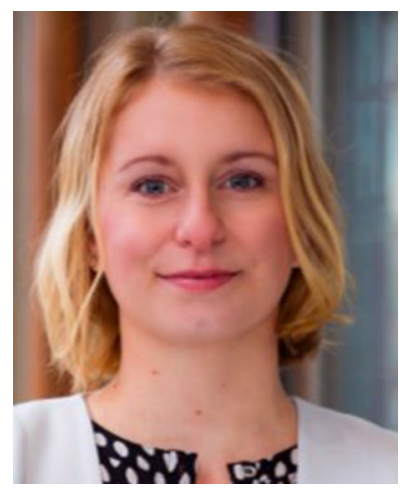

Katharina Metzner is M.Sc. (Biotechnology) and received her $\mathrm{PhD}$ at the University Leipzig, Germany in 2020. She is currently a post-doctoral researcher at the Institute of Pharmacology and Clinical Pharmacy, GoetheUniversity Frankfurt am Main, Germany. Her research combines electrophysiological and behavioral approaches to investigate the mechanisms of pain and itch signalling. 